\title{
Protection of Copper Alloy Condenser Tubes by Coating
}

\author{
Wasan Alkaron ${ }^{1}$, Qais A. Reshack ${ }^{2}$ \\ \{w.alkaron@stu.edu.iq ${ }^{1}$, qais.rashck@uobasrah.edu.iq $\left.{ }^{2}\right\}$ \\ Technical Institute of Basra, Southern Technical Unversity ${ }^{1}$ \\ College of Engineering, University of Basrah ${ }^{2}$
}

\begin{abstract}
The protective coating acts as a layer against erosion, corrosion, and fouling associated with scale deposits. In this study, two laboratory test rigs were installed one for the corrosion rate estimation and another for evaluation of the heat transfer resistance. Three different types of epoxy resin were employed for coating tube surface interiors using different ratios of resin to solvent to produce different coat thicknesses. The results obtained from the corrosion rate and heat transfer resistance measurements showed that the epoxy coating type (a) (ratio of 2: 1 epoxy: solvent ) is efficient in reducing the corrosion rate to $21.1 \times 10^{-2} \mathrm{mpy}$; for example, the efficiency of $92.2 \%$ and the heat transfer resistance increased from $12.88 \times 10^{-4}$ to $18.37 \times 10^{-4} \mathrm{~m}^{2} \mathrm{~K} / \mathrm{W}$ compared to other types of coating.
\end{abstract}

Keywords: condenser tube, copper alloy, corrosion rate, epoxy coating, heat resistance.

\section{Introduction}

The coating technique has been widely used in recent years to form a protective film by some resins. Internal tubes coated with thin-film thickness can improve the heat transfer rate and the overall performance of condenser tubes. The coating tends to inhibit the passage of oxygen through the coating which is inert to chemical or biological attack and protected from scaling and corrosion [1,2]. Tube coating offers an obvious advantage to re-tubing. The most advantages of coating are:

1. Tubes coating eliminated any further corrosive influence of the water upon the copper alloy tube surfaces. Therefore, tubes having up to $80 \%$ loss of metal can be successfully coated, re-condition, and returned to service.

2. The addition of thin-film produces no significant effect deterioration in heat transfer efficiency.

3. Depending on the application and fluid parameters, the polymer coating has a service life of 10-12 years.

4. The polymer will reduce the surface tension; this inhibits the attachment of foreign debris and microbiological growth to the tube wall.

5. Return plugged, leaking tubes to the service. Plugging can cause side effects such as heart rate efficiency reduction, flow pattern changes, and increased velocity.

6. Produce a very economical alternative to retubing. Retubing of condenser tubes requires a long time, and it is very expensive, costing millions of dollars in large condenser units [3], [4]. 


\section{Experimental Work}

\subsection{Specimens Preparation}

A condenser tube segment each of $1.25 \mathrm{~mm}$ thickness and $25.40 \mathrm{~mm}$ outer diameter were taken from the Hartha power station. Tube samples used in the present experimental work were admiralty brass $(\mathrm{AB})(\mathrm{C} 44300)$ having the chemical composition shown in Table 1 . The tubes are cut using an electric cutter into 21 pieces each $10 \mathrm{~cm}$ in length. These pieces are used to test the corrosion rate in the presence and absence of an epoxy coat. Seven samples of $1 \mathrm{~m}$ are used $1 \mathrm{~m}$ length were used for coating inner tubes with different epoxy resins to test the heat transfer resistance.

Table 1. The chemical composition of the used admiralty brass sample was taken from the Hartha power station condenser.

\begin{tabular}{|c|c|c|c|c|c|}
\hline \% Cu & \%Zn & \%Sn & \%Fe & \%Pb & \%As \\
\hline 70.3 & 28.3 & 1.1 & 0.2 & 0.05 & 0.05 \\
\hline
\end{tabular}

\subsection{Specimens Coating Procedure}

Before surface coating, the surface of tubes samples was subjected to the following procedure:

a) Washing and drying at room temperature.

b) Preparing coating material by blending epoxy resin, hardener, and thinner, using variable ratios of resin to solvent as $2: 1$ and 4:1, with a constant adding of hardener in each case in a ratio of 0.5 to facilitate curing of the epoxy. The tube samples were closed from one end and filled with a coating material. Then, the coating material was drained by rotating the tube samples which were left to dry for 24 hours at room temperature. Fig 1 shows the application of different coating materials on admiralty brass samples.

\section{Corrosion Rate}

Using the following equation, corrosion rates were calculated using weight loss methods under various parametric environmental circumstances of exposure duration and fluid velocity $[5]$.

$\mathrm{CR}=\left(\mathrm{K}^{*} \mathrm{~W}\right) /(\mathrm{T} * \mathrm{~A} * \mathrm{D})$

Where $\mathrm{CR}$ is the corrosion rate (mpy), $\mathrm{K}$ is a constant $\left(3.45^{*} 10^{6}\right), \mathrm{T}$ is the time of exposure (hr), $\mathrm{W}$ is weight loss $(\mathrm{g}), \mathrm{A}$ is surface area $\left(\mathrm{cm}^{2}\right)$ and $\mathrm{D}$ is the density of specimen $\left(\mathrm{g} / \mathrm{cm}^{3}\right)$. The protection efficiency conferred by coat can be calculated from the following formula [5].

$\%$ Efficiency $=\left(\mathrm{CR}_{\mathrm{o}}-\mathrm{CR}_{\mathrm{i}}\right) /\left(\mathrm{CR}_{\mathrm{o}}\right) * 100$.

Where $\mathrm{CR}_{\mathrm{o}}$ and $\mathrm{CR}_{\mathrm{i}}$ are the corrosion rates of the metal in the presence and absence of the coat. The corrosion rate of uncoated and coated samples with different thicknesses of epoxy resins 
was estimated using the treatment test rig shown in Fig 2. All samples were connected using flexible tubes. The outer surfaces of tube samples were insulated by Teflon to eliminate oxidation due to exposure to atmospheric conditions. The corrosion rates were determined under various conditions of the exposure time and fluid velocity [6], [7].
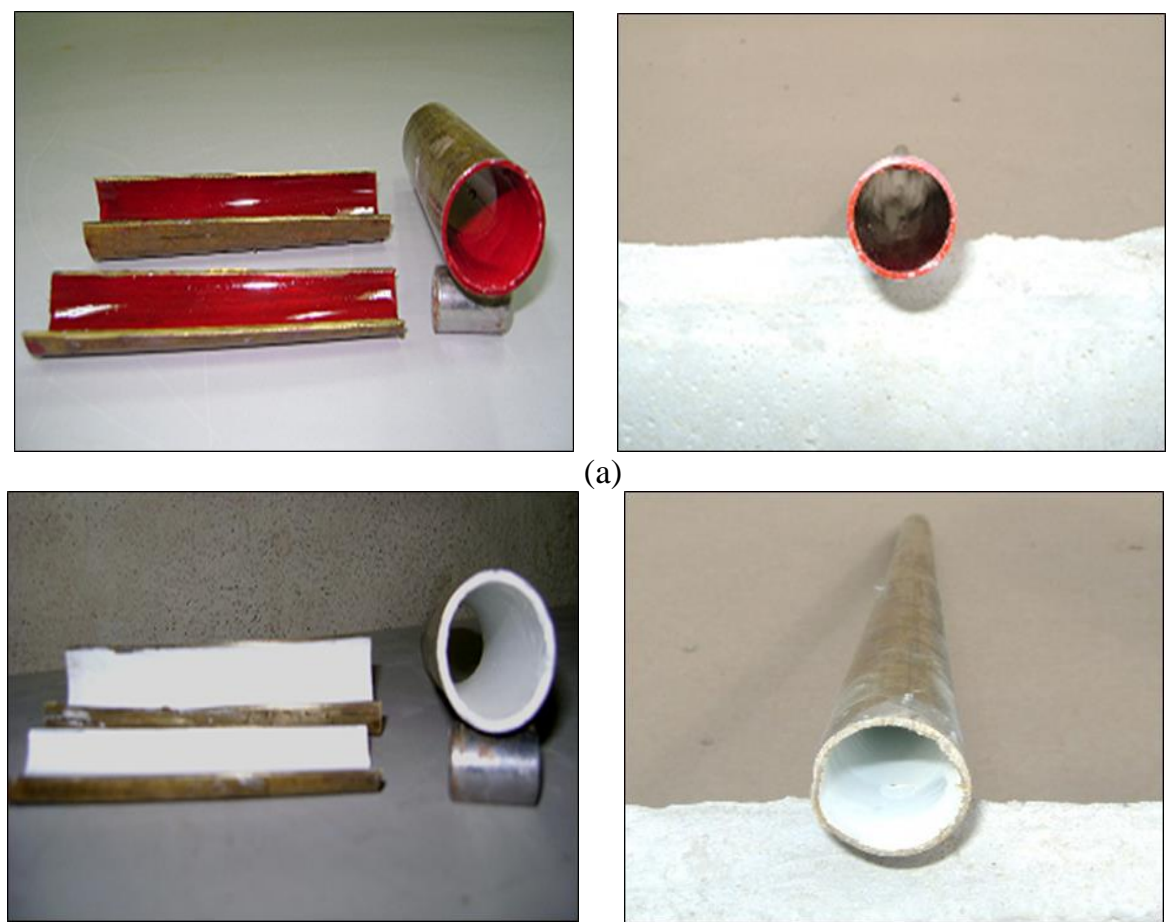

(b)
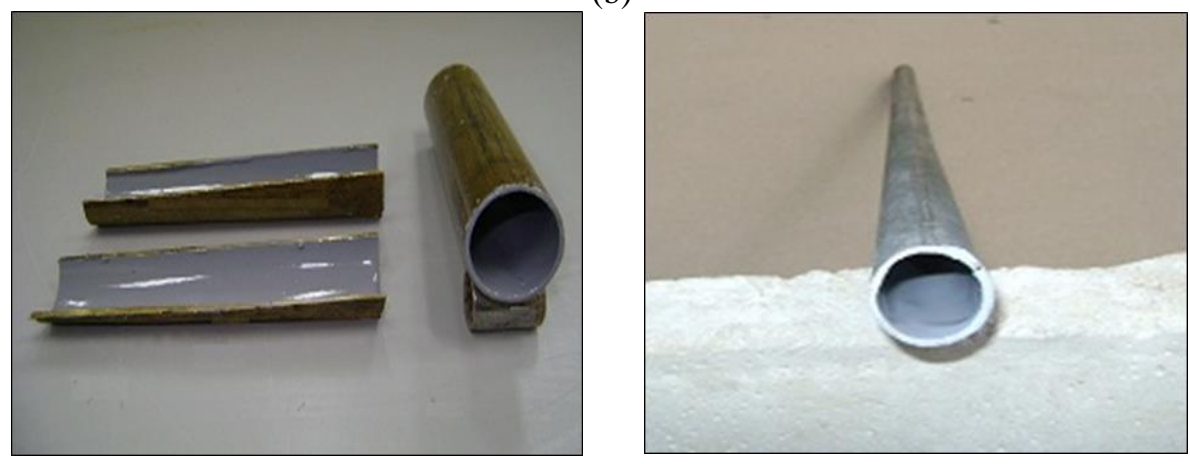

(c)

Fig 1. Application of different coating materials on admiralty brass (a) Epoxy resin type (a), (b) Epoxy resin type (b), and (c) Epoxy resin type (c). 


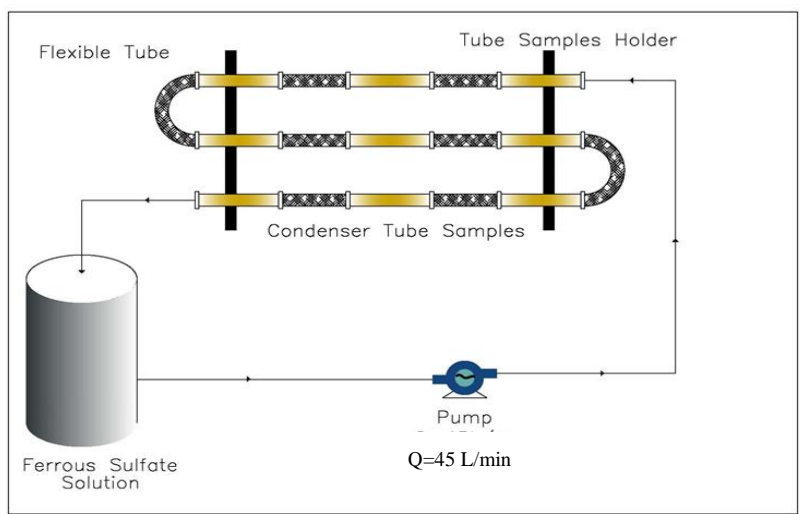

Fig 2. Schematic diagram of test rig used to estimate the corrosion rate.

\subsection{Effect of exposure time}

The samples' corrosion rates were calculated as a function of exposure time. The water velocity in the recirculation system was increased to $1.6 \mathrm{~m} / \mathrm{s}$. After a 7-day extension of the test period, the samples were removed from the rig and scales were removed with emery paper and cotton cloth. The corrosion rate was calculated using the weight loss determined. The experiment was then repeated for a total of seven days. All of the tests were carried out at a temperature of $25 \pm 2$ ${ }^{\circ} \mathrm{C}$ degrees Celsius..

\subsection{Effect of fluid velocity}

The effect of velocity on the corrosion rate was studied at four different velocities $(0.8,1.2,1.6$, and $1.8 \mathrm{~m} / \mathrm{s}$ ), Fluid velocity was calculated as follow:

$\mathrm{Q}_{\mathrm{t}}=\mathrm{V}_{\mathrm{m}} / \mathrm{t}$.

Where $\mathrm{Q}_{\mathrm{t}}$ is the volumetric flow rate $\left(\mathrm{m}^{3} / \mathrm{s}\right), \mathrm{V}_{\mathrm{m}}$ volume of a vessel $\left(\mathrm{m}^{3}\right)$, and $\mathrm{t}$ is the time $(\mathrm{s})$.

$\mathrm{u}=\mathrm{Q}_{\mathrm{t}} / \mathrm{a}$.

The velocity $(\mathrm{m} / \mathrm{s})$ is given by $\mathrm{u}$, while the cross-section area is given by a. $(\mathrm{m} 2)$. To modify the specified velocity required in each situation, the flow rate was varied using a controlled valve. Each test velocity was performed for seven days at a pace of five hours each day. The corrosion rate was determined using the weight loss data. At a temperature of $27 \pm 2^{\circ} \mathrm{C}$, the experiment was carried out.

\section{Heat Transfer Resistance}

A heat transfer resistance (HTR) test rig assembled in at college of engineering, Basra university shown in Fig 3 consisted of the following parts:

1. Heating Element: The coil resistance is placed within an electric insulator and wounded at a distance of $12 \mathrm{~cm}$ on the external surface of each test tube. To produce varied levels of heat power, three types of coil resistance were used. The heating 
element is sealed off from the outside world, allowing all of the heat to pass through the tube wall and into a stream of running water from a reservoir.

2. Thermocouples: Three thermocouples were inserted under the heating element to measure the temperature of the heated surface (Ts), while the other two thermocouples were placed in the test tube's intake and outflow to measure the temperature of the bulk water $\left(\mathrm{T}_{\mathrm{b}}\right)$

3. Cooling System: It's a closed-loop system that includes a cooling water reservoir, two tiny centrifugal pumps, and a cooler. A bypass return to the related reservoir is used to manually control the flow to the test section. The water runs through the cooler after passing past the test portion. This cooler was used to keep the cooling water at the desired temperature before returning it to the reservoir.

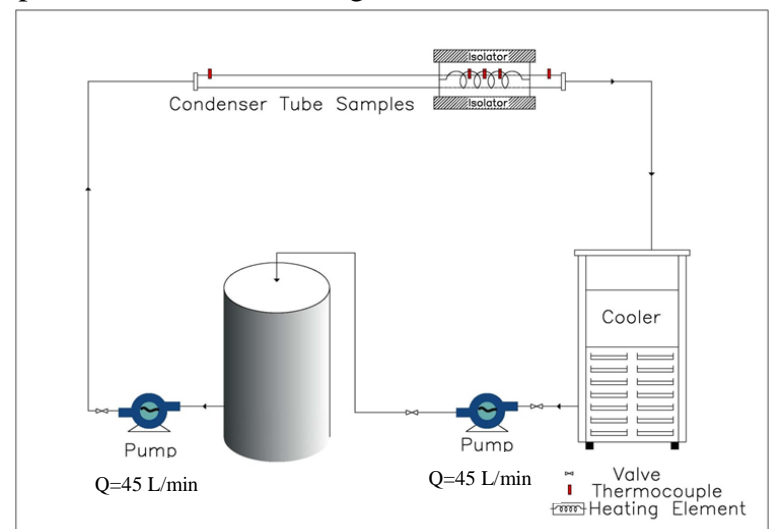

Fig. 3. The schematic diagram for the test rig was used to determine the heat transfer resistance.

The requirements of the thermal procedure can be detailed as:

1. Surface Finish: To remove tarnish coatings and provide a smooth, clean surface finish, all of the tested tube parts are abraded with emery paper grad 400. This was done to ensure that the HTR measurement was related to the inner diameter surfaces, rather than being confounded by tarnish layers on the outer diameter..

2. Temperature Readings: The average temperature readings of three thermocouples placed under the heating element were used to calculate the temperature of the heated surface (Ts). The average temperature readings of the entrance and outflow were used to determine the bulk water temperature $(\mathrm{Tb})$.

3. Heat Flux: The heating element applied a heat flux of $880,726,628 \mathrm{~W}$ via the external surface of the tube under test. Coil resistance was measured with a digital multimeter with an accuracy of $(0.001 \mathrm{~m})$, and current was measured using a digital clamp metre with an accuracy of (0.001 A). The heating element's power input is equal to

Input Power $=\mathrm{V} * \mathrm{I}$.

(5)

Or

$$
=\mathrm{I}^{2} * \mathrm{R} \text {. }
$$

4. Adjusted Velocity: Water was recirculated at a known velocity from the reservoir through the tested tube portion.

The following equation [8] was used to determine the heat transfer resistance HTR for each run: 
Ts is the temperature of the heated surface $(\mathrm{K}), \mathrm{Tb}$ is the temperature of bulk water $(\mathrm{K})$, and Q is the applied heat flux, where A is the area of the heated surface $(\mathrm{m})$, Ts is the temperature of the heated surface $(\mathrm{K}), \mathrm{Tb}$ is the temperature of bulk water $(\mathrm{K})$, and $\mathrm{Q}$ is the applied heat flux (W). The HTR values for each tube were calculated using data from four separate test runs at four distinct velocities $(0.8,1.2,1.6$, and 1.8$) \mathrm{m} / \mathrm{s}$. The steady-state was reached in about 2 hours for each test run.

\section{Determination of the Coating Thickness}

It was aimed to determine the thickness of the applied epoxy resin coat on the inner tube surface. Therefore, tube thickness before and after coat application was measured to determine the thickness deference which refers to the thickness of the coat. The coated tube was longitudinally cut and the thickness was measured by Micrometer in different positions.

\section{Results and Discussion}

\subsection{Corrosion Rate Measurement Results}

Under dynamic test conditions, the exposure time and velocity were found to alter the corrosion rate results. Both of these factors are studied at specified working ambient conditions.

\section{A) Effect of Exposure Time based on Corrosion Rate}

The results of corrosion rate of admiralty brass $(\mathrm{AB})$ tube samples coated with different types of epoxy resins (Case 1) type (a,b, and c) in which epoxy coating material having a ratio of 2:1 epoxy: solvent is shown in Fig 4. Although the coating material covered the whole surface, the surface still shows a very small value of corrosion rates. This can be attributed to the barrier properties and low permeability of the epoxy coating layer [8]. The corrosion rates at a test period of 35 days are $(27.0,18.8$, and 14.8$) * 10^{-2} \mathrm{mpy}$, for epoxy (a, b, and c) respectively. Thus, it was found that the efficiency of each type of epoxy coating in reduction of the corrosion rate was $90.4 \%, 93.3 \%$, and $94.7 \%$ at 35 days maximum exposure time of for epoxy (a, b, and c) respectively, as compared with untreated samples. Therefore, type (c) epoxy resin showed a greater reduction in corrosion rate than types $a$ and $b$. 


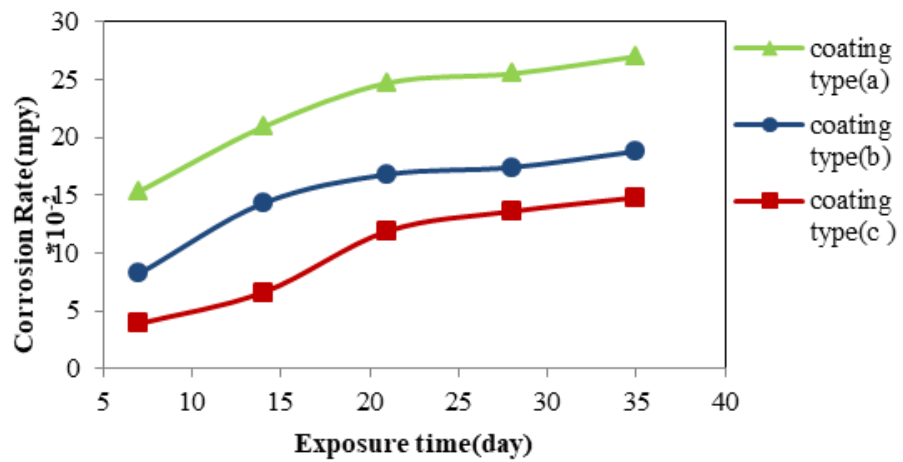

Fig. 4. Corrosion rate as a function of time for epoxy coated (Case1) types a, b and c, at velocity $1.6 \mathrm{~m} / \mathrm{s}$ of filtered water, $\mathrm{pH} 7.6$, at $25^{\circ} \mathrm{C}$.

The comparison between the corrosion rate value of the three types of epoxy resins (Case2) types $(a, b$, and c) in which epoxy coating material having a ratio of 4:1 epoxy: solvent is shown in Fig 5.

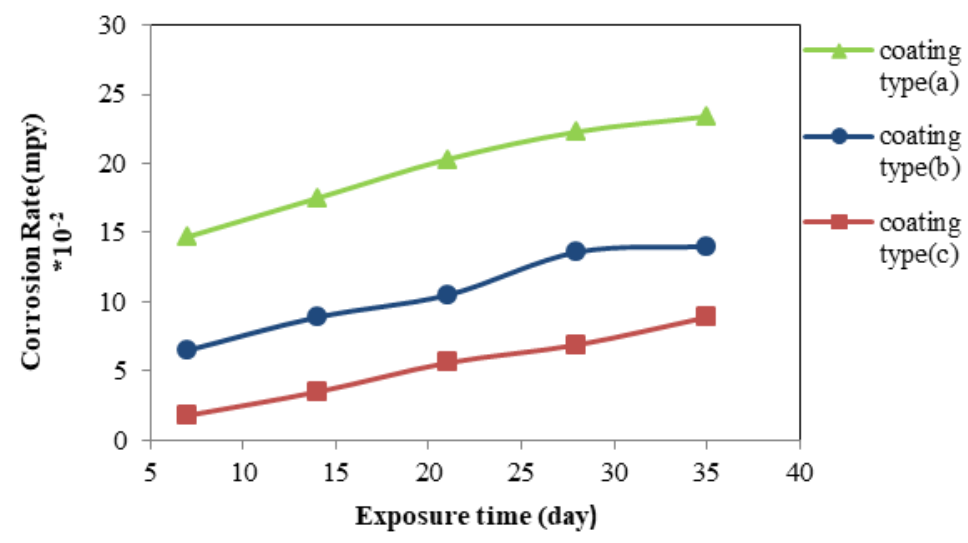

Fig. 5. Corrosion rate as a function of time for epoxy coated (Case2) types a, b and c at velocity $1.6 \mathrm{~m} / \mathrm{s}$ of filtered water, $\mathrm{pH} 7.6$, at $25^{\circ} \mathrm{C}$.

The results indicated that the corrosion rate was slightly increased with increasing exposure time, the coating materials tend to inhibit the passage of oxygen through the coating layer and reduced further corrosive influence of the environment $[1,2]$. The 35 days corrosion rates are $(23.4,14.0$, and 8.9$) \times 10^{-2}$ mpy for epoxy types (a, b, and c) respectively. The efficiency of each type of epoxy coating in reduction of corrosion rate was $91.7 \%, 95.2 \%, 96.8 \%$ at a maximum exposure time of 35 days for epoxy types ( $a, b$, and c)respectively, as compared with untreated samples. Thus, type (c) epoxy resin showed higher reduction efficiency the corrosion rate than types (a) and (b) i.e. it can be regarded as an excellent protective coating.

\section{B) Effect of velocity on corrosion rate}


The corrosion rates of the three types of epoxy resins (Case1) type (a, b, and c) are shown in Fig 6 . The corrosion rates at a velocity of $1.8 \mathrm{~m} / \mathrm{s}$ are $(21.1,13.2,7.8) \times 10^{-2} \mathrm{mpy}$ for epoxy type $(\mathrm{a}, \mathrm{b}$, and c) respectively. The efficiency of each type of epoxy coating in reduction of corrosion rate was $92.2 \%, 95.1 \%, 97.1 \%$, for epoxy types ( $a, b$, and c) respectively, as compared with untreated samples. Thus type (c) epoxy resin showed a better reduction of corrosion rate than types (a and b). Comparison between corrosion rate of the three types of epoxy resins (Case 2) type (a, b, and c) are shown in Fig 7. The corrosion rates at maximum velocity used of $1.8 \mathrm{~m} / \mathrm{s}$ are $(17.6,10.2$, 6.2) $\times 10^{-2}$ mpy for epoxy type ( $a, b$, and c) respectively, and it was found that the efficiency of the epoxy coating in minimizing the corrosion rate was found $93.5 \%, 96.2 \%, 97.7 \%$ for epoxy type ( $a, b$, and c) respectively. Thus, type (c) epoxy resin exhibits a lesser corrosion rate and higher efficiency than types ( $a$ and $b)$.

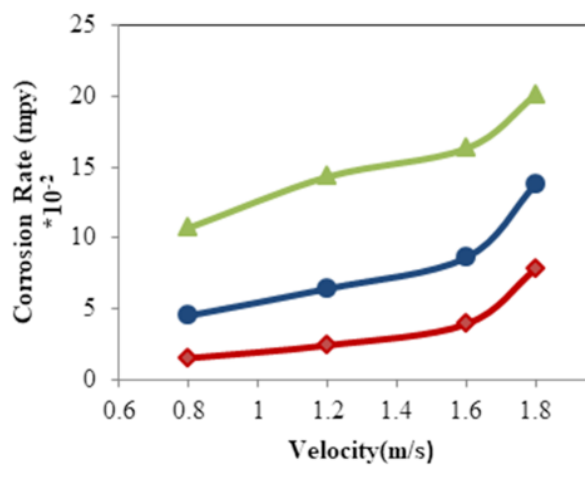

Fig. 6. Corrosion rate as a function of velocity for epoxy coating (Case1) types a, b and c, in filtered water for 7 days, $\mathrm{pH} 7.6$, at $27^{\circ} \mathrm{C}$.

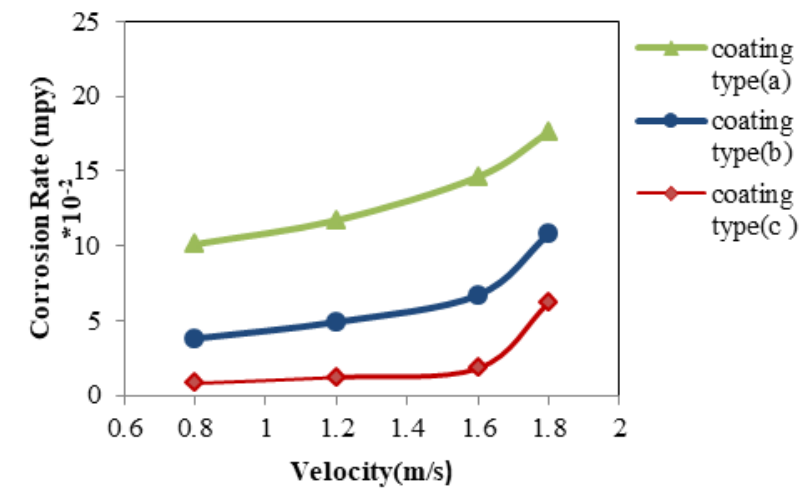

Fig. 7. Corrosion rate as a function of velocity for epoxy coating (Case 2) types a, b and c, in filtered water for 7 days, $\mathrm{pH} 7.6$, at $27^{\circ} \mathrm{C}$.

\section{C) Comparisons of the Corrosion Rates}

A comparison is made between the results of the corrosion rates of uncoated and coated samples, to select the best type of coating that reduces the corrosion rate to the minimum value. 
i. By comparison of the corrosion rates values as a function of time for uncoated and coated samples, Figs 8 and 9 showed that epoxy coating (Case 2) type (c) is the best coat for reduction of corrosion rate of $\mathrm{AB}$.

ii. By comparison the corrosion rate values as a function of velocity for uncoated and coated samples. Figs 10 and 11 showed that epoxy coating (Case 2) type (c) is the best coat for the reduction of corrosion rate of $\mathrm{AB}$. This can be attributed to the high adhesive force against the turbulent flow, excellent corrosion resistance to flowing water, and excellent adhesion properties [10]. On other hand, it was showed that the corrosion rates of epoxy coating (Case 2) are lower than the corrosion rate of epoxy coating (Case 1), as the ratio of epoxy: solvent increased, the thickness of the coating film increased which result in a reduction of the corrosion rate. Since the heat transfer in condenser tubes is a very important factor, so select the best type of protective coating did not rely only on the reduction of the corrosion rate, but also depending on the loss of heat transfer rate imposed by the presence of coat layer, this will be discussed in the following section.

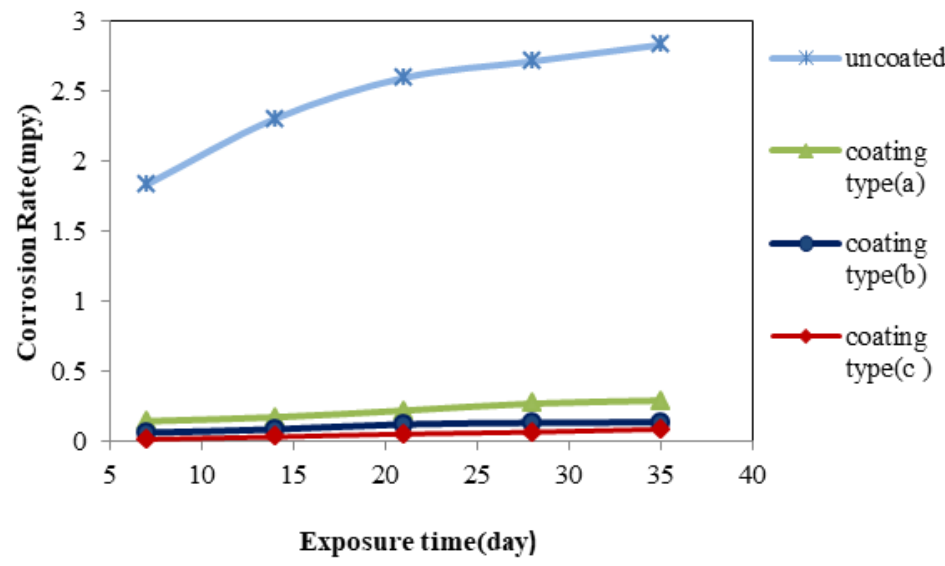

Fig. 8. Comparison of the corrosion rate with time for uncoated, coated admiralty brass with epoxy coating (Case 1) types a, b and c.

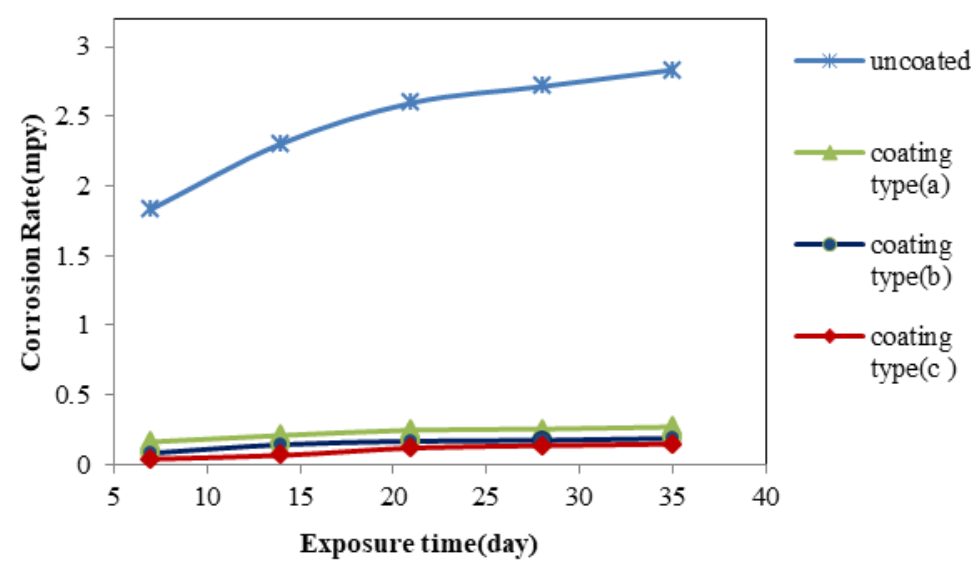

Fig. 9. Comparison of the corrosion rate with time for uncoated, coated admiralty brass with epoxy coating (Case 2) types a, b and c. 


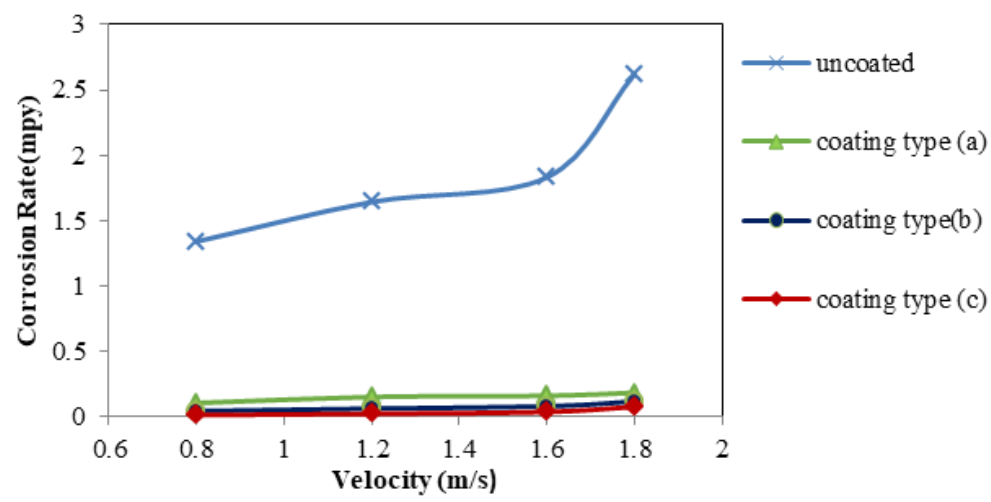

Fig. 10. Comparison of the corrosion rate with velocity for uncoated, coated admiralty brass with epoxy coating (Case 1) types a, b and c

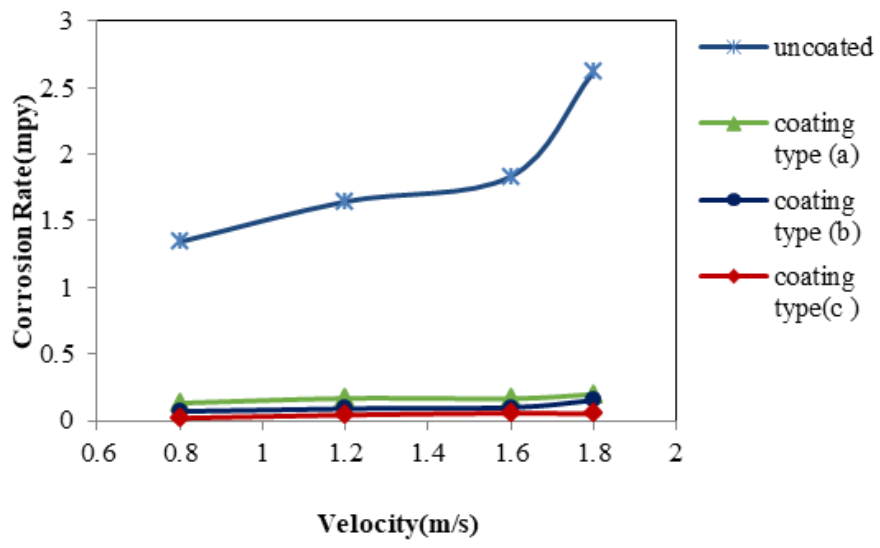

Fig. 11. Comparison of the corrosion rate with velocity for uncoated, coated admiralty brass with epoxy coating (Case 2) types a, b and c.

\subsection{Resistance of Heat Transfer}

Heat transfer resistance with a velocity of uncoated and coated AB tube samples with epoxy resins are shown in Fig 12 to Fig 18. In general, increasing water velocity led to a reduction of the heat transfer resistance, the amount of heat which able to flow through the wall tubes depended upon the temperature difference which exists between the heated surface and cooling water temperature. If the heat flux remains constant, the increased water velocity led to a reduction of temperature difference [11]. However, the temperature difference is a function of heat transfer rate, so lesser temperature difference led to higher heat transfer rate and lesser HTR [8]. The obtained results were found agreed well with that reported by Phull [8]. It was observed that increasing applied heat will led to reduction of heat transfer resistance in each type of (uncoated and coated) tube samples. This can be attributed to that the increase of the heat flux led to increase the amount of the heat transfer rate through the wall tubes, so that the heat transfer resistance values will be reduced [12]. 


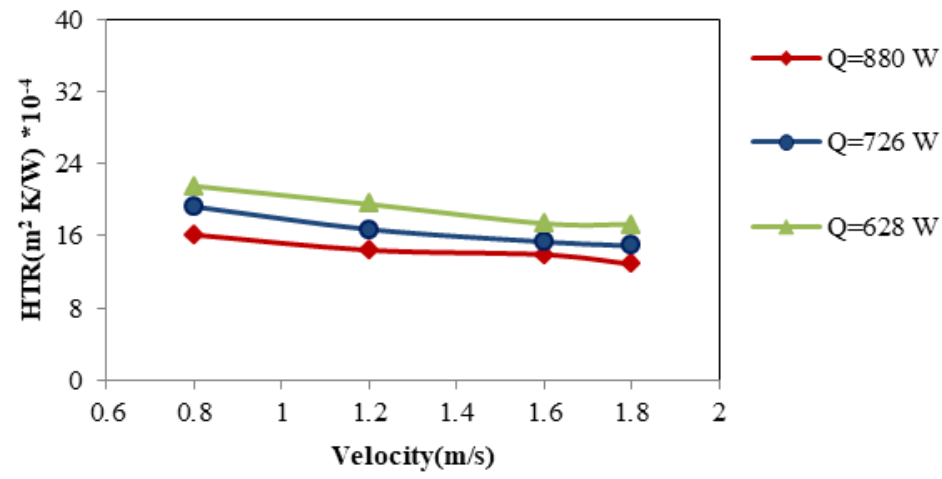

Fig. 12. Heat transfer resistance with velocity for uncoated admiralty brass tubes at different applied heat, at $30^{\circ} \mathrm{C}$.

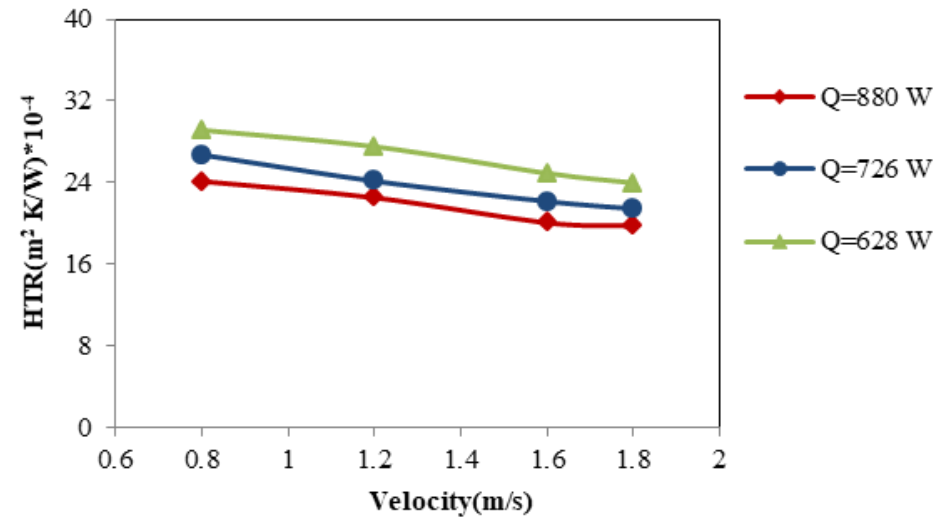

Fig. 13. Heat transfer resistance with velocity for epoxy coating (Case 1) type (a) at different applied heat, at $30^{\circ} \mathrm{C}$.

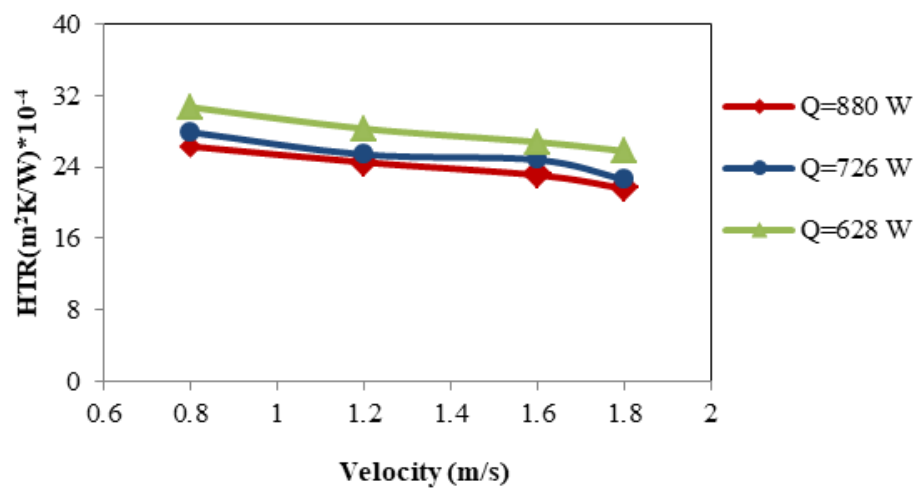


Fig. 14. Heat transfer resistance with velocity for epoxy coating (Case 2) type (a) at different applied heat, at $30^{\circ} \mathrm{C}$.

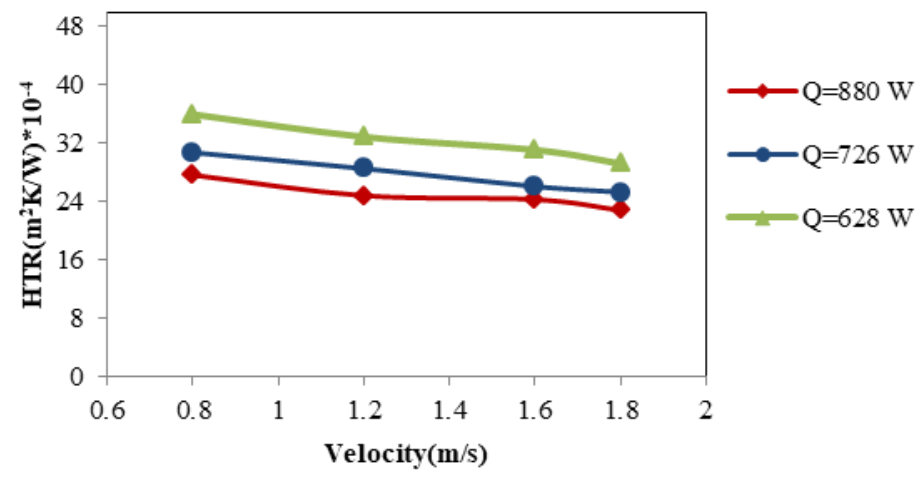

Fig. 15. Heat transfer resistance with velocity for epoxy coating (Case 1) type (b) at different applied heat, at $30^{\circ} \mathrm{C}$.

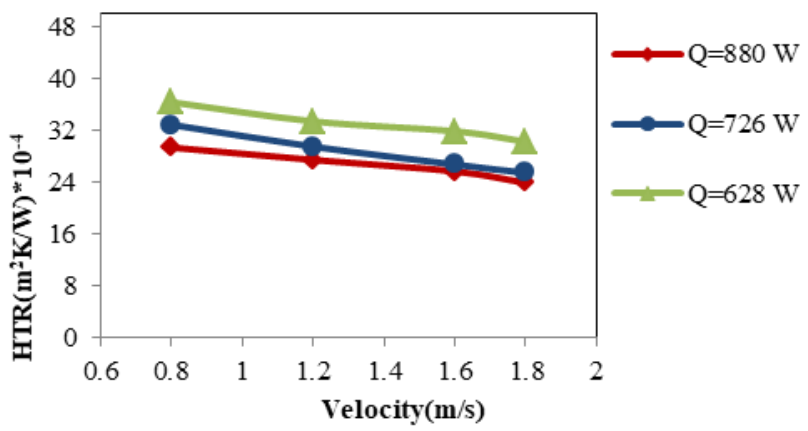

Fig. 16. Heat transfer resistance with velocity for epoxy coating (Case 2) type (b) at different applied heat, at $30^{\circ} \mathrm{C}$.

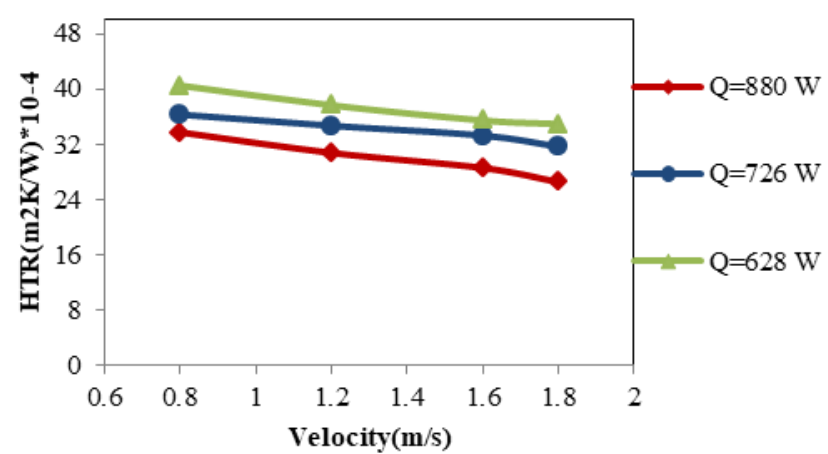

Fig. 17. Heat transfer resistance with velocity for epoxy coating (Case 1) type (c) at different applied heat, at $30^{\circ} \mathrm{C}$. 


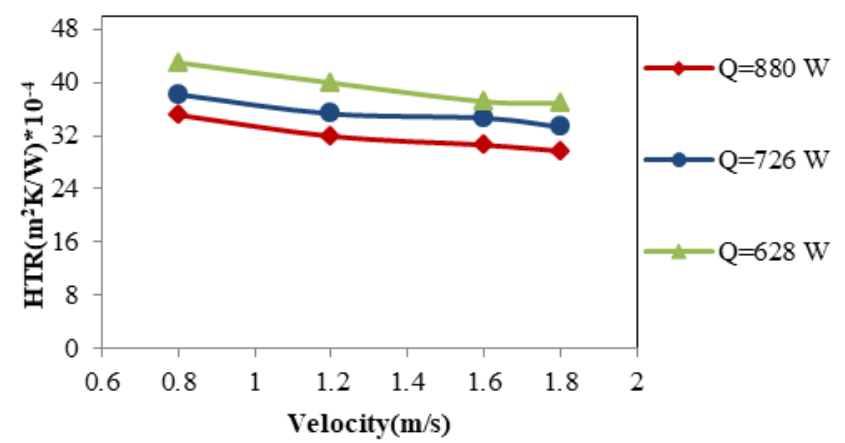

Fig. 18. Heat transfer resistance with velocity for epoxy coating (Case 2) type (c) at different applied heat, at $30^{\circ} \mathrm{C}$

\subsection{Comparison of HTR Results}

Comparison of HTR results between uncoated and coated AB tubes is carried out to show the best type of protective coating that has less amount of HTR value. Figures 19 and 20 show the HTR findings for uncoated and coated AB tubes at different heat applications $(880,726$, and $628) \mathrm{W}$. The figures reveal that increasing applied heat reduced HTR; for example, the greater applied heat of $880 \mathrm{~W}$ during the experiment had the lowest HTR when compared to the HTR at 726 and $628 \mathrm{~W}$, respectively. Fig 19 indicates that the HTR at $880 \mathrm{~W}$ and $1.8 \mathrm{~m} / \mathrm{s}$ are $(12.88$, $18.37,22.88,26.51,21.67,23.95$, and 29.98)*1 $10^{-4} \mathrm{~m}^{2} . \mathrm{K} / \mathrm{W}$ for uncoated, coated, epoxy (Case 1) types (a, b, c) and epoxy (Case 2) types (a, b, c) respectively. It is clear from Fig 19 that epoxy coating (Case 1) type (a) showed a lesser HTR value than other types of epoxy coating. HTR through the wall tubes depended on tube thickness [8], higher coating thickness led to an increase in the temperature difference between heated surface and bulk water temperature that reduced the heat transfer rate and increased heat transfer resistance. These results showed good approximation with the study of Nagata and Sato [10].

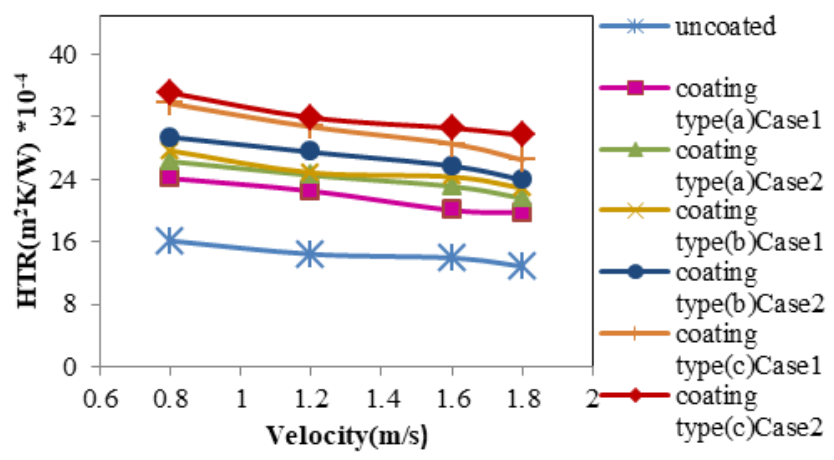

Fig. 19. Comparison of the effect of velocity on heat transfer resistance of uncoated and epoxy-coated samples at applied heat of $880 \mathrm{~W}$. 


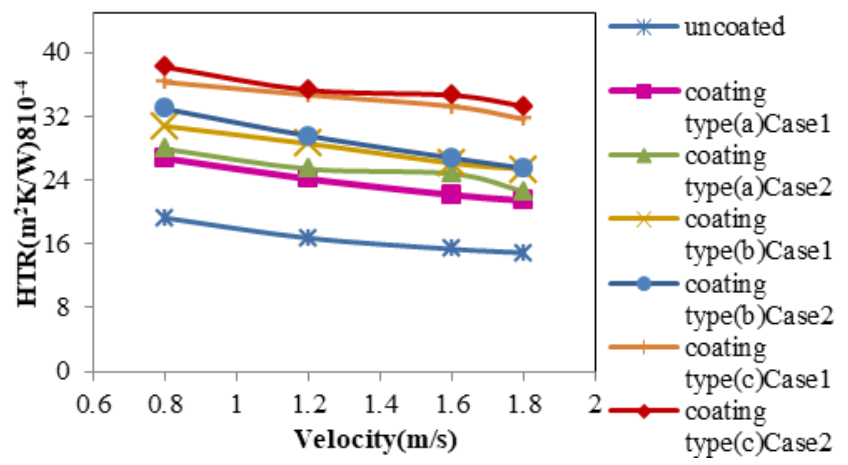

Fig. 20. Comparison of the effect of velocity on heat transfer resistance of uncoated and epoxy-coated samples at applied heat of $726 \mathrm{~W}$.

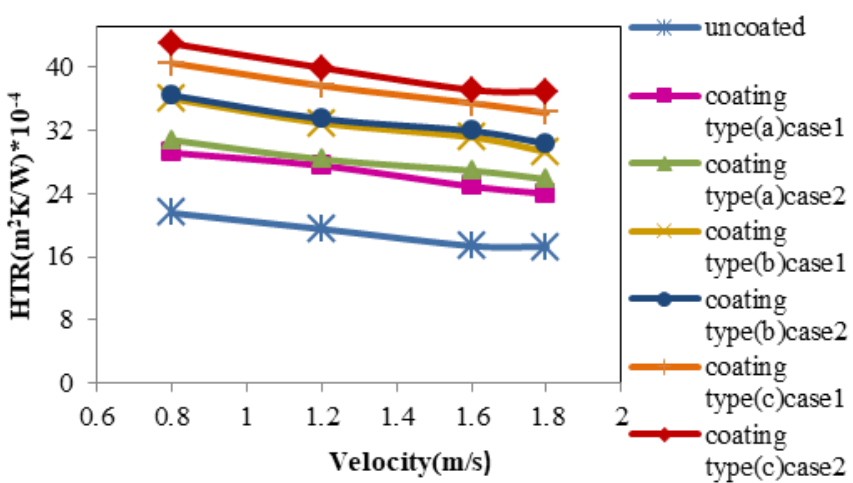

Fig. 21. Comparison of the effect of velocity on heat transfer resistance of uncoated and epoxy-coated samples at applied heat of $628 \mathrm{~W}$.

\section{Results of Coating Thickness Measurement}

The results of thickness measurements of the three types of epoxy resins (Case 1 and 2) are shown in Table 2 and Table 3. The results indicated that the range of thickness is $0.02-0.07 \mathrm{~mm}$, 0.04-0.12 mm, and 0.08-0.18 $\mathrm{mm}$ for epoxy resin (Case 1) type (a, b, c) respectively, while the range of thickness for epoxy resin(Case 2) is $0.20-0.30 \mathrm{~mm}, 0.27-0.39 \mathrm{~mm}$ and $0.37-0.50 \mathrm{~mm}$ for epoxy resin type $(a, b, c)$ respectively. The coating thickness relies on adhesion properties and the density of resin. The high density and excellent adhesion led to a high value of coating thickness. By comparison between epoxy coating (Case1 and 2), it appeared that epoxy resin (Case 1) (ratio of 2:1 epoxy: solvent) showed minimum thickness than (Case 2) (ratio of 4:1 epoxy: solvent).

Table 2. The thickness of epoxy resin (Case1) type (a, b, c) (all in mm)

\begin{tabular}{cccccc}
\hline \multicolumn{2}{c}{ (a) } & \multicolumn{2}{c}{ (b) } & \multicolumn{2}{c}{ (c) } \\
\hline $\begin{array}{c}\text { Thickness } \\
\text { after coat }\end{array}$ & $\begin{array}{c}\text { Thickness } \\
\text { of coat }\end{array}$ & $\begin{array}{l}\text { Thickness } \\
\text { after coat }\end{array}$ & $\begin{array}{c}\text { Thickness } \\
\text { of coat }\end{array}$ & $\begin{array}{c}\text { Thickness } \\
\text { after coat }\end{array}$ & $\begin{array}{c}\text { Thickness } \\
\text { of coat }\end{array}$ \\
\hline 1.27 & 0.02 & 1.29 & 0.04 & 1.33 & 0.08 \\
1.28 & 0.03 & 1.31 & 0.06 & 1.35 & 0.10 \\
1.30 & 0.05 & 1.32 & 0.07 & 1.37 & 0.12
\end{tabular}




\begin{tabular}{llllll}
1.30 & 0.05 & 1.34 & 0.09 & 1.38 & 0.13 \\
1.32 & 0.07 & 1.37 & 0.12 & 1.43 & 0.18 \\
\hline
\end{tabular}

Table 3. The thickness of epoxy resin (Case 2) type (a, b, c).

\begin{tabular}{cccccc}
\hline \multicolumn{2}{c}{ (a) } & \multicolumn{2}{c}{ (b) } & \multicolumn{2}{c}{ (c) } \\
\hline $\begin{array}{c}\text { Thickness } \\
\text { after coat } \\
(\mathbf{m m})\end{array}$ & $\begin{array}{c}\text { Thickness } \\
\text { of coat } \\
(\mathbf{m m})\end{array}$ & $\begin{array}{c}\text { Thickness } \\
\text { after coat } \\
(\mathbf{m m})\end{array}$ & $\begin{array}{c}\text { Thickness } \\
\text { of coat } \\
(\mathbf{m m})\end{array}$ & $\begin{array}{c}\text { Thickness } \\
\text { after coat } \\
(\mathbf{m m})\end{array}$ & $\begin{array}{c}\text { Thickness of } \\
\text { coat } \\
(\mathbf{m m})\end{array}$ \\
\hline 1.45 & 0.20 & 1.52 & 0.27 & 1.62 & 0.37 \\
1.49 & 0.24 & 1.54 & 0.29 & 1.64 & 0.39 \\
1.49 & 0.24 & 1.58 & 0.33 & 1.68 & 0.43 \\
1.53 & 0.28 & 1.60 & 0.35 & 1.69 & 0.44 \\
1.55 & 0.30 & 1.64 & 0.39 & 1.75 & 0.50 \\
\hline
\end{tabular}

The results indicated that decreasing ratio of resin: solvent led to reduction of the coating thickness. Minimum coating thickness was useful for reduction of the heat transfer resistance, epoxy resin (Case1) type (a) with a film thickness of $0.02-0.07 \mathrm{~mm}$ showed lesser heat transfer resistance than other types of epoxy resins.

\section{Conclusions}

We can conclude the folowing:

1) It is found that increasing epoxy resin to solvent ratio increases coating thickness, which improved corrosion resistance of $\mathrm{AB}$, but increased heat transfer resistance.

2) It is found that epoxy resin type (a) (ratio of 2:1 epoxy: solvent) is efficient in reducing the corrosion rate to $21.1 * 10^{-2}$ mpy such as the efficiency of $92.2 \%$ and the heat transfer resistance increased from $12.88 \times 10^{-4}$ to $18.37 \times 10^{-4} \mathrm{~m}^{2} . \mathrm{K} / \mathrm{W}$ i.e. epoxy coating resistance of $5 \times 10^{-4}$ $\mathrm{m}^{2} . \mathrm{K} / \mathrm{W}$ compared to other types of coating that showed more increase in heat transfer resistance due to increase in film thickness.

\section{References}

[1] B. Yu, Y. Liu, L. Wei, X. Zhang, Y. Du, Y. Wang, S. Ye, "A Mechanism of Anti-Oxidation Coating Design Based on Inhibition Effect of Interface Layer on Ions Diffusion within Oxide Scale", Coatings, 2021; vol. 11, no. 454.

[2] H. Rein, M.Rourke, G. John, "The Antifouling Effects of Copper-Oxide Filler Incorporated Into Paint-Based Protective Films Applied to Steam Surface Condenser Tubes", Journal of Thermal Science and Engineering Applications, February, 2018.

[3] Tube Coating With Teflon An Outstanding Alternative to Condenser and Chiller tube Replacement, Technical Bulletin, 2002.

[4] D. Chugunkovl, G. Seyfelmlyukova1, A. Skurikhina1, "Method and device for applying protective coatings to heat exchange tubes of system heaters", IOP Publishing Ltd, Journal of Physics; vol. 1370, 2nd International Conference on Fusion Energy and Plasma Technologies ; 7-9 October 2019; Moscow, Russian Federation.

[5] S. Gowda, "Multi Scale Effect of Corrosion on Steel Structures", Doctoral dissertation, University of Akron, 2016.

[6] S. Sato, T. Nosetani, "Allowable Water Velocity and Cleanliness Factor of Aluminum Brass Condenser Tube With Ferrous Addition Into Sea Water", Sumitomo Light Metal Industries ,Technical Reports, 1996, pp.11, No.4. 
[7] H. Hack, T. Lee, "The Effect of Ferrous Sulfate on Sulfide-Induced Corrosion of CopperBase Condenser Alloys in Aerated Seawater", Report, Naval Ship Research and Development Center, Maryland, January, 1990.

[8] B. Phull, "The Laque Center for Corrosion Technology Heat Transfer Evaluations of Condenser Tubes", EPRI, Florida Power Corporation, 2004.

[9] L. Fedrizzi, F. Andreatta, F. Paussa, L., Deflorian,F. Maschio, "Heat Exchangers Corrosion Protection by Using Organic Coatings", Progress in Organic Coatings, Italy 2008; vol. 63, pp. 299-306.

[10] K. Nagata, S. Sato, "Experiences of APF Condenser Tubes" Sumitomo Light Metal Industries, 1985, pp.18-20.

[11] M. Lakovic, S. Mitrovic, M. Jovic, "The choice of surface condenser in function of energy efficiency of thermal power plant", International conference Power Plants, Zlatibor; October 2014; Serbia.

[12] S. Sato, "Condenser Biofoling Control ", Symposium, The State of The Art, EPRI, 1990. 